\title{
Construction Elements and Path of Practical Education Model in Universities
}

\author{
Yongliang Wang \\ Center for English Teaching and Research/College English Department, Henan University, Kaifeng, 475004, CHINA
}

Received 7 July 2017 - Revised 15 August 2017 • Accepted 17 September 2017

\begin{abstract}
With the promotion and application of high-tech in large-scale manufacturing, aerospace, machinery manufacturing, medical equipment, biotechnology enterprises, enterprises have increasingly growing demand for high-quality skilled personnel, while practical talents are in great shortage, and embarrassing situation of "no recruitable talent" is often a case. Practical education reflects the real demand of national economic development and reform. In-depth analysis of the current development status of practical education model in colleges and universities reveals practical problems such as rigid education system, lack of platform resources and detachment from practical demand. Therefore, it is necessary to build a good practical educational and cultural environment from the three levels of thought, system and teaching. Efforts should be made to improve practice teaching platform, comprehensively enhance "order-oriented" talent training, adhere to the employment-oriented, scientific and practical evaluation system as a guarantee, make comprehensive innovation in practical education model and improve teaching quality. It is necessary to build a strong inner support structure from the aspects of thought, system and teaching, to improve educational and cultural environment from thought, system, teaching, and accelerate the reconstruction of practical educational innovation practice platform. Centering on construction goal of practical teaching model and practical talent training, the practical teaching platform of colleges and universities needs to explore the construction mechanism featuring mutual convergence, mutual cooperation, mutual benefit and win-win of theoretical and social needs, comprehensively highlight practical teaching characteristics, strengthen students' practical ability to lay the foundation for their future career development; conduct "order-oriented" training in line with actual employment needs, provide new ideas and implementation programs for "order-oriented" training, strengthen "order-oriented" teaching effect; strengthen evaluation system practicality within the framework of school-enterprise cooperation.
\end{abstract}

Keywords: practical education, educational model, cultural environment, order-oriented

\section{INTRODUCTION}

In the face of the rapid development of information industry, "made in China 2025" strategic task put forward that all walks of life are in urgent need of management talent, professional and technical personnel, innovative talent and even entrepreneurial talent. For instance, Gao Ming pointed out that the ratio of job vacancies of different technical levels to job seekers is above 1, among which, that for technician, senior technician, senior worker is 2.04 , 1.9 and 1.83 (Csaszar, Levinthal, 2016), respectively. These factors have accelerated the innovation and development

(C) Authors. Terms and conditions of Creative Commons Attribution 4.0 International (CC BY 4.0) apply. Correspondence: Yongliang Wang, Center for English Teaching and Research/College English Department, Henan University, Kaifeng, 475004, China.

\. Godfreyeducation@163.com 


\section{Contribution of this paper to the literature}

- A specific analysis is made for the first time on the components of practical education model, which has passed validation.

- Discussion is made on the path to achieve the model by combining the components, with specific approaches given.

- Vague discussions are avoided with theoretical basis provided for the next specific study.

of practical education model in colleges and universities. Efforts should be made to accelerate the construction of practical educational and cultural environment in depth, concentrate outstanding forces of all parties, strengthen and perfect the innovation and practice teaching platform. For instance, Song Xiaojin pointed out that by integration of "production" and "teaching" in the education process, students can receive real experience in this new model, enhance the ability to link theory with practice, so as to fully reverse the practical situation where practical education model in colleges and universities is not up to standard, thus substantially promoting improvement in college graduate employment quality (Duran, Barnes, Corkery, 2015).

\section{LITERATURE REVIEW}

From the social point of view, practical education model in colleges and universities is to provide appropriate talents to all walks of life. It emphasizes unity of knowledge and practice, including knowledge objectives, competency objectives and quality objectives. Oriented to the first line senior practical talents in production, construction, management, service, the connotation of objective is: with serving regional development as the purpose, promoting employment and entrepreneurship as the orientation, docking industry demand as a benchmark, meeting job requirements as the basis, and with strengthening professional ability as the basis, focus on complexity and application of knowledge, highlight the cultivation of practical ability and innovative spirit (Liu, Zheng, 2015). However, current awareness of the educational model is still inadequate, mainly including the following states: for example, compared to traditional knowledge education, literature is only understood as more emphasis on students' application of technical skills in actual occupation, plus comprehensive improvement in proportion of practical teaching. That is, relative to academic studies, more focus is given to employment. The literature argues that compared to service, practical education targets at industry, emphasizes fitting in specialty, so that it can take foot in industry characteristics, obtain good employment performance, cooperate closely with local industry, business production, research and development, service, and provide point-to-point professional talent. However, it only proposes solution to problems from the perspective of application, and the awareness is one-sided. The literature only emphasizes technical "specialty talents", integrates technical content of practical education in the traditional knowledge curriculum system, and adds contents of professional characteristics, job responsibilities to achieve effective convergence between university practical education and future employment, which fails to completely depart from the main body of theoretical knowledge (Li, 2017).

\section{METHODS}

In order to further validate the elements of practical education model, it is necessary to carry out empirical method design. After replacing the existing non - practical education with the practical educational environment, the factor impact modeling method is as follows:

$$
P S A_{i}=P C_{i} \cdot S E_{i}
$$

In the above formula, $P S A_{i, t}$ is the practical education correlation intensity of the sample school, $P C_{i}$ is the judgment variable. If the school adopts the practical teaching method, it indicates that the model has correlation, $P C_{i}=1$. Otherwise, $P C_{i}=0 . S E_{i}$ is correlative background intensity variable of practical education, and five-point rating valuation value is determined according to correlation intensity of teaching means. 
Table 1. The correlation test result

\begin{tabular}{|c|c|c|c|c|c|c|}
\hline Variable & $\Delta W C_{i, t}$ & $P S A_{i, t}$ & $A L R_{i, t}$ & $S I Z E_{i, t}$ & $A R_{i, t}$ & $P T_{i, t}$ \\
\hline$\Delta W C_{i, t}$ & 1 & -- & -- & -- & -- & -- \\
\hline$P S A_{i, t}$ & $0.0125^{\star *}$ & 1 & -- & -- & -- & -- \\
\hline$A L R_{i, t}$ & 0.0093 & -0.0095 & 1 & -- & -- & -- \\
\hline$S I Z E_{i, t}$ & $0.0198^{\star \star *}$ & 0.0098 & $-0.0099 * *$ & 1 & -- & -- \\
\hline$A R_{i, t}$ & 0.0101 & $0.0101^{* \star}$ & 0.0101 & 0.0101 & 1 & \\
\hline$P T_{i, t}$ & 0.0101 & -0.0101 & 0.0101 & $0.0101^{* \star}$ & 0.0101 & 1 \\
\hline
\end{tabular}

\section{Measurement Model for Platform Factor Influencing Degree}

The main idea of the model is that the platform influence degree is the linear estimate of practical education, and the influence continuity is measured by acceptance degree converted by platform influence degree. The model expression is:

$$
\Delta W C_{i, t}=\alpha_{0}+\alpha_{1} C F O_{i, t-1}+\alpha_{2} C F O_{i, t}+\alpha_{3} C F O_{i, t+1}+\varepsilon
$$

In the above formula, $\Delta W C_{i, t}$ indicates change in the teaching platform, i.e. the number of practical courses taught in the school year $\mathrm{t}-1$ and $\mathrm{t}$ of school $\mathrm{i} /$ the total number of courses; $C F O_{i, t-1}, C F O_{i, t}, C F O_{i, t+1}$ respectively indicates the ratio of participating students in $t-1, t, t+1$ school year to the student number with satisfactory feedback (liu, and Tian, 2017).

\section{Talent Impact Modeling}

In this study, with the change of talents as dependent variable, students' social adaptability after acceptance of practical teaching as independent variable, student grade, school size, feedback registration, acceptance time, constraint variables are selected as control variables. Due to the large sample size and data size of this study, the model of practical education impact on social adaptability is constructed based on the cross-sectional model, specifically as follows:

$$
\Delta W C_{i, t}=\beta_{0}+\beta_{1} P S A_{i, t}+\beta_{2} A L R_{i, t}+\beta_{3} S I Z E_{i, t}+\beta_{4} A R_{i, t}+\beta_{5} P T_{i, t}+\beta_{6} \text { Industry }_{i, t}+\vartheta
$$

In the above formula, $\triangle W C_{i, t}$ is a substitute variable for social adaptability, $P S A_{i, t}$ is the talent adaptability, $A L R_{i, t}$ is the negative impact factor of talents, $S I Z E_{i, t}$ is the scale of talent, $A R_{i, t}$ is rate of feedback received by school, $P T_{i, t}$ is teaching time, Industry $y_{i, t}$ is a dummy variable. $\beta_{0}$ is a constant term, $\beta_{i}$ is a variable coefficient, $\vartheta$ is a random interference term.

\section{RESULTS}

The practical education schools in China are the study objects. In order to avoid impact of collinearity between variables on accuracy of the results, we first carried out correlation test on the variables. The results are shown in Table 1.

It can be seen from Table 1 that there is no significant collinearity between the variables. Social adaptability is related to the teaching environment and is positively related to the platform. According to Model 3, the impact of talent on practical education can be obtained. The results are shown in Table 2.

As can be seen from Table 2, practical education variable $\Delta W C_{i, t}$ has significant correlation with talent $P S A_{i, t}$ at $1 \%$ level, has significant correlation with platform size $S I Z E_{i, t}$ at $5 \%$ level, indicating that the factor is affected by multiple factors. 
Table 2. The regression results of the study

\begin{tabular}{|c|c|c|c|c|}
\hline \multicolumn{5}{|c|}{ Dependent Variable: $\Delta W C_{i, t}$} \\
\hline Variable & Coefficient & Std. Error & t-Statistic & Prob. \\
\hline$\beta_{0}$ & 8.334 & 0.545 & 4. 5433 & 0.0015 \\
\hline$P S A_{i, t}$ & 0.0432 & 0.3568 & 5.7643 & 0.0065 \\
\hline$A L R_{i, t}$ & 0.0043 & 0.1543 & 1.7623 & 0.6783 \\
\hline$S I Z E_{i, t}$ & 0.6543 & 0.2964 & 1. 9875 & 0.0235 \\
\hline$A R_{i, t}$ & 0.0044 & 0.6532 & 1.7762 & 0.0246 \\
\hline$P T_{i, t}$ & 0.0853 & 0.0598 & 2. 5732 & 0.0255 \\
\hline Industry $_{i, t}$ & 0.0945 & 0.2270 & 2.6753 & 0.0360 \\
\hline
\end{tabular}

\section{DISCUSSIONS}

\section{Good Practical Campus Education and Cultural Environment}

Campus culture environment can achieve educational effects of value leadership, publicity and guidance in a subtle way, but campus culture deposited by different types of colleges and universities is very different, so the potential role of campus culture construction in practical educational model cannot be ignored, which should be designed as an important part of the educational model (Lin, Han, Huang, et al. 2017). In the practical education model, students pay more attention to their own growth, have willing to exchange, want to change, can easily accept information, but do not know how to judge, analyse and use information. However, especially in terms of quality, technology development, production management process demands more personal responsibility, moral quality and professionalism and philosophy from practical personnel. First, the construction of practical education and cultural environment in colleges and universities should adhere to the socialist core values as the guide, fully integrate with the excellent cultural traditions, advanced world thinking, strengthen campus content richness, taste elegance, and adhere to student orientation, create good culture of innovation and humanities, and then form an "encirclement" from the three levels of system, material, spirit, so that students really feel connotation and spirit of practical education concept (Punckt, Bodega, Kaira, et al. 2015). Second, practical education culture is also reflected in quality aspect. Quality awareness, as the fundamental task in development of all walks of life in the whole society, has been deeply rooted, and thus quality culture is also a part of campus education culture. Its core is purpose, stability, that is, what is the purpose of practical education, what is the quality standard of personnel training and what kind of technical indicators can be adopted for explanation. In the course of future development, it is necessary to make constant conclusion, analysis and improvement, thus forming a changing growth path (Şevki, Fidanboy, Kurt, 2016).

\section{Perfect Practical Teaching Practice Platform in Universities}

Practical education in colleges and universities has a positive role in meeting the needs of China's social and economic development for high-level, practical talents, and promoting the process of popularization of higher education in China. Different from the research-based education and teaching education, practical education serves local economic and social demands, therefore pays more attention to and urgently needs practice platform to strengthen the coherence of theoretical teaching and practical application. In the face of the increasing number of demand, practical teaching practice platform of colleges and universities should be improved by combining teaching, research and future occupations. In particular, it should focus on practical needs of practice, center on the growth law of practice, learning, re-practice and relearning, fundamentally ensure that students have access to abundant, high-quality practice opportunities, so that students acquire and consolidate theoretical knowledge which are truly understood and innovated in the course of practice (Wei, 2016; Li, 2016). Of course, openness of practical teaching platform is also crucial to stimulation of students' self-initiative to participate in practical activities. After all, despite excellent teaching methods and perfect platform, it is students to complete the activities. Students in the open model can choose, design and deploy resources of practice platform, which not only helps students strengthen their practical ability, but also helps cultivate students' sense of responsibility and cooperation (Wang, Han, 2016). 


\section{Employment-Oriented Practical Talents Training}

In the face of the serious employment pressure of college students, development of new industries and adjustment of industrial structure, practical education model of colleges and universities must pay close attention to future professional characteristics of students, then innovate the educational model, adjust the professional structure and comprehensively enhance practical talents training quality (Yong, 2017). Aiming at the technical requirements of the national strategic emerging industries and the future career of students: First, strengthen systematicness, solidarity and broadness of students' professional knowledge system, and ensure that students have certain research and innovation capability in the future employment. Education contents should be practical, so that students are competent for a business or social position after completion of each course. Teaching content must be very clear. Meanwhile, pay more attention to the construction of characteristic professional courses, encourage characteristic professional teachers to carry out corresponding practical research, so that curriculum construction is fuller and richer to adapt to and meet needs of characteristic practical talents. Second, ensure hierarchy in practical talent training. The demand for talent knowledge structure, technical capacity, quality and literacy in industrial transformation is more diversified, while personal demand for ideals, job search and development is individualized. Practical training model should be actively optimized to meet the complex twoway demand, protect the future survival and development of college students. Also, students' knowledge, quality and ability characteristics should be optimized with employment-orientation. In particular, enable students to form sensible, rational awareness of future employment, develop sound job concept, so as to improve the matching between talent and occupation, and achieve the ultimate goal of practical teaching model.

\section{CONCLUSION}

\section{Improving the Educational and Cultural Environment from Thought, System and Teaching}

Good education and cultural environment represents brand connotation of a university. To build practical education "brand effect", strengthen the competitiveness of university education model, efforts should be made to create a strong internal support structure from multiple aspects of thought, system and teaching, eliminate "false, empty" model of practical education in colleges and universities. First is the docking of concept of educational ideas, as idea is the leader of action. In the era of knowledge economy, the most important strategic resource for strategic emerging industry is information, knowledge, science and technology / creativity, so practical talents training demands possession of theoretical basis of professional knowledge, and grasp of inter-disciplinary processional knowledge and technology. Talents of different industries or professions are greatly different in thinking mode, values and even modes of action. Therefore, practical teaching model should gradually give new interpretation to vocabularies of professional, disciplinary, academic concept with vocational guidance as the core. Because there is deep-rooted "time principle" in practical educational model, efforts should be made to cultivate students' ability to produce correct response in the face of professional activities, and then form the teaching idea with knowledge application as the core. Second, establish career-oriented teaching management system. Practical talent training should pay more attention to the use of theoretical knowledge to solve practical problems. The traditional university management system has a bias to academic rigor, theoretical definition, which cannot meet innovation requirements of practical education model. Efforts should be made to promote the shift in university education center with future career, industry development as the core management system. Third is marketization change of teaching model. Emphasis should be given to open, flexible, diverse and diversified pattern of personnel training model. Domestically, there are such main personnel training models as dual certificate system, orderoriented, production and research integration, working and study alternation style, school-enterprise comprehensive implementation of " $2+1$ ". Meanwhile, "double teacher" team construction should be strengthened, so that teachers engage in practical training in workshops. Also, workers and technical staff can be invited to give lectures in university classrooms, forming school-enterprise talent exchange mechanism to create a marketized, industrial new pattern of education, help students build social market awareness, and strengthen students' practical value concept and social adaptability. 


\section{Accelerate the Reconstruction of Educational Innovation Practice Platform for Practical Universities}

Centering on the construction goal of practical education model and practical talent cultivation, practical teaching platform of colleges and universities needs to explore the construction mechanism featuring mutual convergence, mutual cooperation and mutual benefit between theory and social demand, comprehensively highlight practical teaching characteristics, and strengthen students' practical ability to lay a good foundation for their future career development. First, change practical teaching philosophy, make real-time, dynamic analysis based on the social development situation and future development trend of social environment, effectively manage the relationship between theoretical knowledge, practical ability, comprehensive literacy, so as to ensure consistency with construction thinking, development direction of practical education platform, promote the cultivation of practical talents, create new features of highly dynamic training, ensure the core foothold and development momentum of practice platform reconstruction. Second, cultivate practical ability, literacy of applied teachers, which largely determines the effective operation of innovation practice platform. Teachers' understanding towards professional concept, industry development and professional spirit will directly act on daily practice of teaching process, causing potential impact on students' thoughts and behavior. The practice platform of colleges and universities should implement the talent introduction plan extensively, strengthen actual combat experience of the faculty and gradually move towards diversified development, thus establishing an effective and close relation between practice teaching and practice. Third, innovative practice teaching links. Extracurricular combination has always been an important part of practical teaching model. We must change the past model in which only senior students have the opportunity for participation. Appropriate practical teaching contents should be provided since students are enrolled, with richer technical skills integrated since basic skills to reduce students' difficulty in understanding and adapting to practical education, thus truly reflecting the "going out" teaching idea. Fourth, strengthen mechanism for cooperation of practice platforms among colleges and universities. The biggest difficulty in the construction of college practice platform is the lack of resources, so only "partial" investment is possible. Nevertheless, by regional university cooperation, practice platform can give priority to the development of strengths in accordance with the characteristics of colleges and universities, with weak practice teaching dependent on practice platform of other colleges and universities, thus forming good result of complementary advantages, mutual benefit and common development.

\section{Conduct "Order-Oriented" Training to Meet the Actual Employment Needs}

If the college students are defined as "commodity", then satisfaction of "customer" including society, industry, business towards "commodity" will directly reflect the quality of university personnel training. "Orderoriented" practical personnel training idea is put forward in response to the "customer satisfaction" concept. Giving in-depth attention to the customer's multiple demands, it regards enterprise factors as the key to the training of personnel in colleges and universities. From the perspective of functional adaptability, social enterprise demand has more prominent importance, which is an important part of new normal construction of innovation development, sustainable development of modern practical education to conform to the new trend of educational development in the era. First is docking of specialty provision and regional industry. The proposal of regional industrial base provides more effective support to practical education model in colleges and universities, such as cultural industry base, biotechnology industry base, media imaging industry base, etc. which can provide very clear "blueprint" for talent needs characteristics, quantity, technical skills, future development. College education is to provide specialty based on the "blueprint", provide more "order-oriented" talent for various industries, while solving the serious employment pressure and enhancing specialty, flexibility and pertinence in professional teaching. Second, improve the "order-oriented" talent transfer quality monitoring system. Regardless of the changes, college practical education always stresses that personnel training should be very inclusive, while employers pay more attention to pursuit of interests, so students stepping into career will show great changes due to the harsh environment. Quality monitoring is to find a breakthrough, grasp dynamic changes in enterprise requirements, student workplace information, to provide new ideas and implementation programs for "orderoriented" personnel training and strengthen "order-oriented" teaching effect. 


\section{Strengthen the Practicality of Evaluation System within the Framework of School- Enterprise Cooperation}

Establishment of a scientific, effective and practical evaluation system is an important subject of practical education model in colleges and universities. With the in-depth development of practical education model, the integration of production and education has become the main way of practical education in colleges and universities. The closer and effective cooperation between universities and enterprises brings more effective and practical ideas to the traditional education evaluation system. Based on the cooperation between schools and enterprises, efforts should be made to implement the training standard together, build curriculum system together, undertake practice teaching together, promote graduate employment together, with employer participating in quality evaluation and ultimately achieving seamless docking between graduate employment and industry (trade) development needs. Efforts can be made mainly from the following aspects to improve the evaluation system in the framework of school-enterprise cooperation, and effectively enhance practicality of evaluation effect: First is government level evaluation. As the leader and participant of the school-enterprise cooperation, government departments have an irreplaceable role in practical teaching model of colleges and universities, so the government departments should occupy a certain weight of evaluation mainly in environmental conditions, policy system, supervision and guidance. Second is the evaluation of university itself. As the main body of education and personnel training, colleges and universities occupy higher evaluation weight, with evaluation indexes around specialty type, teacher strength, curriculum content, educational resources and practical training, professional fit and so on. Third is enterprise, industry evaluation. As the employer, business, industry have the most intuitive feelings towards practical talents output by colleges and universities, whose evaluation contents are the most practical and scientific. Hence, the weight of evaluation is consistent with that of colleges and universities. Business, industry evaluation is centered on students' technical skills, professional quality, teamwork, communication, etc. Through the government, university, business evaluation of applied education, practicality of the evaluation system can be improved to better adjust practical education model in colleges and universities. Rapid changes in the socio-economic structure bring more diverse demand levels and specialties for talents. Therefore, to meet the talent needs of all walks of life has become a criteria and goal with key considerations for practical education model in colleges and universities. Starting from practical education and cultural environment, innovation practice platform, efforts should be made to gradually build a job-oriented practical talent training model, effectively enhance internal and external customers' satisfaction towards practical education model of colleges and universities, to strengthen university talent training brand and reputation.

\section{ACKNOWLEDGEMENT}

The project is supported by the national social science fund of China - Research on teachers' professional development from the perspective of PLC (No. BDA150021).

\section{REFERENCES}

Csaszar, F. A., \& Levinthal, D. A. (2016). Mental representation and the discovery of new strategies. Strategic Management Journal, 37, 2031-2049.

Duran, C. J., Barnes, S. J., \& Corkery, J. T. (2015). Chalcophile and platinum-group element distribution in pyrites from the sulfide-rich pods of the Lac des Iles Pd deposits, Western Ontario, Canada: Implications for postcumulus re-equilibration of the ore and the use of pyrite compositions in exploration. Journal of Geochemical Exploration, 158, 223-242.

Epp, C. D., \& Bull, S. (2015). Uncertainty Representation in Visualizations of Learning Analytics for Learners: Current Approaches and Opportunities. IEEE Transactions on Learning Technologies, 8, 242-260.

Huang, X. S. (2016). Tao xingzhi three education concept of professional education Angle analysis. Chinese professional technology education, 13, 108-110.

Huo, L. J. (2015). The thinking of education system of modern profession under the concept of education for life. Chinese professional technology education, 10, 10-17. 
Li, G. (2017). American comprehensive school health work mode. School health in China, 38, 323-326.

Li, Y. L. (2016). Research on social factors in the cultivation of college applicability talents. Research of heilongjiang high education, 5, 69-71.

Lin, Y., Han, P., Huang, Y., Yuan, G. L., Guo, J. X., \& Li, J. (2017). Source identification of potentially hazardous elements and their relationships with soil properties in agricultural soil of the Pinggu district of Beijing, China: Multivariate statistical analysis and redundancy analysis. Journal of Geochemical Exploration, 173, 110-118.

Liu, C. L., \& Zheng, Y. K. (2015). In the background of education, the construction and evaluation factor analysis of the teachers' competence evaluation model in the private colleges. Chinese professional technology education, $5,80-84$

Liu, Y., \& Tian, Z. Q. (2017). The strengthening of the function of education in college English is based on resource optimization theory. Research of heilongjiang high education, 12, 162-164.

Punckt, C., Bodega, P. S., Kaira, P., \& Rotermund, H. H. (2015). Wildfires in the Lab: Simple Experiment and Models for the Exploration of Excitable Dynamics. Journal of Chemical Education, 92, 1330-1337.

Şevki, D., Fidanboy, H., \& Kurt, E. (2016). Exploration of the Chaotic Behaviour in a Buck-Boost Converter Depending on the Converter and Load Elements. Journal of Electronic Materials, 45, 3889-3899.

Wang, Y. S., Han, B. (2016). The strategic transfer of education's overall development focus of university entrepreneurship is put forward. Research of heilongjiang high education, 6, 84-86.

Wei, C. D. (2016). College mathematics education system function construction in the professionalized reform. Research of heilongjiang high education, 2, 75-77.

Yong, Z. Z. (2017). Research on the structural elements of education professional skills curriculum standards - and the standard preparation techniques for professional skills courses. Chinese professional technology education, 7, 57-61.

\section{http://www.ejmste.com}

